\title{
Nucleic acids and endosomal pattern recognition: how to tell friend from foe?
}

\author{
Eva Brencicova and Sandra S. Diebold* \\ Peter Gorer Department of Immunobiology, Guy's Hospital, King's College London, London, UK
}

\section{Edited by:}

Nelson Gekara, Umea University,

Sweden

\section{Reviewed by:}

Bastian Opitz, Charite University Medicine Berlin, Germany

Melanie M. Brinkmann, Helmholtz Centre for Infection Research,

Germany

\section{${ }^{*}$ Correspondence:}

Sandra S. Diebold, Peter Gorer Department of Immunobiology, Guy's, King's and St. Thomas' Medical School, Guy's Hospital, King's College London, 2nd Floor Borough Wing, London SE1 9RT, UK e-mail: sandra.diebold@kcl.ac.uk
The innate immune system has evolved endosomal and cytoplasmic receptors for the detection of viral nucleic acids as sensors for virus infection. Some of these pattern recognition receptors (PRR) detect features of viral nucleic acids that are not found in the host such as long stretches of double-stranded RNA (dsRNA) and uncapped single-stranded RNA (ssRNA) in case of Toll-like receptor (TLR) 3 and RIG-I, respectively. In contrast, TLR7/8 and TLR9 are unable to distinguish between viral and self-nucleic acids on the grounds of distinct molecular patterns. The ability of these endosomal TLR to act as PRR for viral nucleic acids seems to rely solely on the mode of access to the endolysosomal compartment in which recognition takes place. The current dogma states that self-nucleic acids do not enter the TLR-sensing compartment under normal physiological conditions. However, it is still poorly understood how dendritic cells (DC) evade activation by self-nucleic acids, in particular with regard to specific DC subsets, which are specialized in taking up material from dying cells for cross-presentation of cell-associated antigens. In this review we discuss the current understanding of how the immune system distinguishes between foreign and self-nucleic acids and point out some of the key aspects that still require further research and clarification.

Keywords: endosomal toll-like receptors, nucleic acids, innate immune activation, autoimmunity, pattern recognition
Viruses are dependent on the host metabolism for replication. As a consequence of this, the carbohydrate and lipid structures associated with viruses are very similar to those of the host and, therefore, do not represent suitable pathogen-associated molecular patterns (PAMP) for innate immune recognition. Instead, the immune system has evolved pattern recognition receptors (PRR) that recognize viral nucleic acids. Viral replication leads to the accumulation of viral replication intermediates in the cytoplasm of infected cells, which trigger cytoplasmic PRR such as the RIG-I-like receptors and various DNA sensors such as DAI, $\mathrm{DExD} / \mathrm{H}$ box family helicases, AIM2-like receptors and cGAS (Kato et al., 2011; Keating et al., 2011; Sun et al., 2013; Wu et al., 2013). These cytoplasmic nucleic acid-sensing PRR initiate the local anti-viral response in the infected tissue. Cells of the innate immune system are recruited to the site of infection and together with local sentinels such as Langerhans cells and dermal dendritic cells (DC) in the skin and interstitial DC in other organs sense the infectious organism by means of PRR such as Toll-like receptors (TLR), which sample exogenous material for the presence of PAMP. PRR-mediated activation of DC by PAMP is thought to be crucial for the initiation of an adaptive immune response against the invading pathogen (Joffre et al., 2009). The requirement for direct activation of DC via PRR ensures that only DC which had direct contact to the infectious organism and present pathogenderived antigens have the capacity to induce the differentiation of $\mathrm{T}$ cells into effector cells. However, in particular situations, indirect activation of DC via inflammasome-induced IL- $1 \beta$ seems to be sufficient to promote the induction of an adaptive immune response as observed upon live influenza A or herpes simplex virus infection in mice (Pang et al., 2013). Similarly, in house dust mite allergen-induced asthma direct TLR-mediated activation is dispensable (Hammad et al., 2009) and it is currently unclear which mechanism allows the immune system to repeal the need for direct activation of DC.

Recognition by cytoplasmic PRR partially depends on features of viral nucleic acids that are absent from mammalian nucleic acids such as $5^{\prime}$ triphosphate groups on short blunt-ended double-stranded RNA (dsRNA) structures recognized by RIG-I and long dsRNA structures recognized by MDA5 (Goubau et al., 2013). However, cytosolic DNA sensors are thought to be unable to distinguish between foreign and self DNA since it was shown that recognition is sequence-independent and unaffected by nucleic acid modifications such as methylation (Ishii et al., 2006; Stetson and Medzhitov, 2006). Furthermore, while DAI (also called DLM-1/ZBP1) was initially described as a Z-DNA-binding protein recognizing the rare left-handed $Z$-form of DNA associated with some viral structures, it was later demonstrated that the right-handed B-form of DNA as seen for self DNA and most commonly found under physiological conditions has the capacity to trigger a cytoplasmic DNA sensor upstream of the stimulator of interferon (IFN) genes (STING) (Schwartz et al., 2001; Ishii et al., 2006; Takaoka et al., 2007). In line with the hypothesis that cytoplasmic sensors are not specific for foreign DNA structures, self DNA induces polyarthritis in mice deficient for DNase II and type I interferon (IFN-I) receptor in a STING-dependent manner (Ahn et al., 2012). Similarly, TLR-mediated recognition 
of nucleic acids relies on molecular patterns that are present in self-nucleic acids as discussed later in more detail (Hornung et al., 2006; Pichlmair et al., 2006; Takaoka et al., 2007). This shows that the immune system has evolved mechanisms to prevent stimulation by self-nucleic acids under normal conditions, but that nucleic acid-sensing PRR can trigger innate immune activation in pathological situations. Thus, aberrant PRR activation by selfnucleic acids poses the risk of driving autoimmunity induction. In this review, we will discuss the current understanding of how the immune system distinguishes between viral vs. self-nucleic acids on the level of endosomal TLR and which mechanisms are involved in preventing autoimmunity induction driven by TLR-mediated sensing of self-nucleic acids under physiological conditions.

\section{ENDOSOMAL TOLL-LIKE RECEPTORS AND THEIR AGONISTS}

The family of endosomal nucleic acid-sensing TLR comprises TLR3, TLR7, TLR8, and TLR9 (Figure 1). While TLR7-9 form all endosomal TLR dependent on the endoplasmic reticulum (ER)resident protein UNC93B1 for trafficking from the ER via the Golgi to the endolysosomal compartment (Figure 3A) (Du et al., 2000; Brinkmann et al., 2007; Kim et al., 2008). Other factors that affect the trafficking of endosomal TLR are the ER chaperone GP96 and PRAT4A (Randow and Seed, 2001; Takahashi et al., 2007; Yang et al., 2007b). For a comprehensive review on TLR trafficking see the review by Lee et al. (2012).

In addition, differential recruitment of adaptor protein complexes (AP) affects post-Golgi trafficking of endosomal TLR. While AP-2 recruitment by TLR9 enables its translocation from the plasma membrane to the endolysosomal compartment, TLR7 trafficking is independent of AP-2 and does not involve transient localization to the plasma membrane, but instead is dependent on AP-4 recruitment (Lee et al., 2013). TLR3 trafficking is again distinct from TLR7 and TLR9 and is independent of PRAT4A and not affected by mutations in UNC93B1 that impair TLR7 and TLR9 trafficking (Takahashi et al., 2007; Fukui et al., 2011). Interestingly, cell specific differences in endosomal TLR trafficking have also been reported. Trafficking of endosomal TLR in plasmacytoid DC (PDC) is dependent on the recruitment of AP-3 and LC-3, which direct the localization of TLR7 and TLR9 to an endosomal compartment specialized in inducing type I IFN in these natural IFN-producing cells (Sasai et al., 2010; Henault et al., 2012).

Once recruited to the endolysosomal compartment, the TLR are rendered functionally active upon cleavage by resident $\mathrm{pH}$ dependent proteases (Ewald et al., 2008; Park et al., 2008). The requirement for cleavage upon arrival in the endolysosomal compartment is thought to prevent activation of the nucleic acidsensing TLR by self-nucleic acids at other locations in the cell or at the cell surface and is regarded as one of the mechanism that prevent aberrant activation of these TLR by self-agonists under physiological conditions. However, once the TLR have been rendered functional through proteolytic cleavage, they cannot distinguish between viral and self-nucleic acids on the basis of structural differences with the exception of TLR3.

TLR3 recognizes viral dsRNA in a sequence-independent manner in form of genomic dsRNA or dsRNA replication

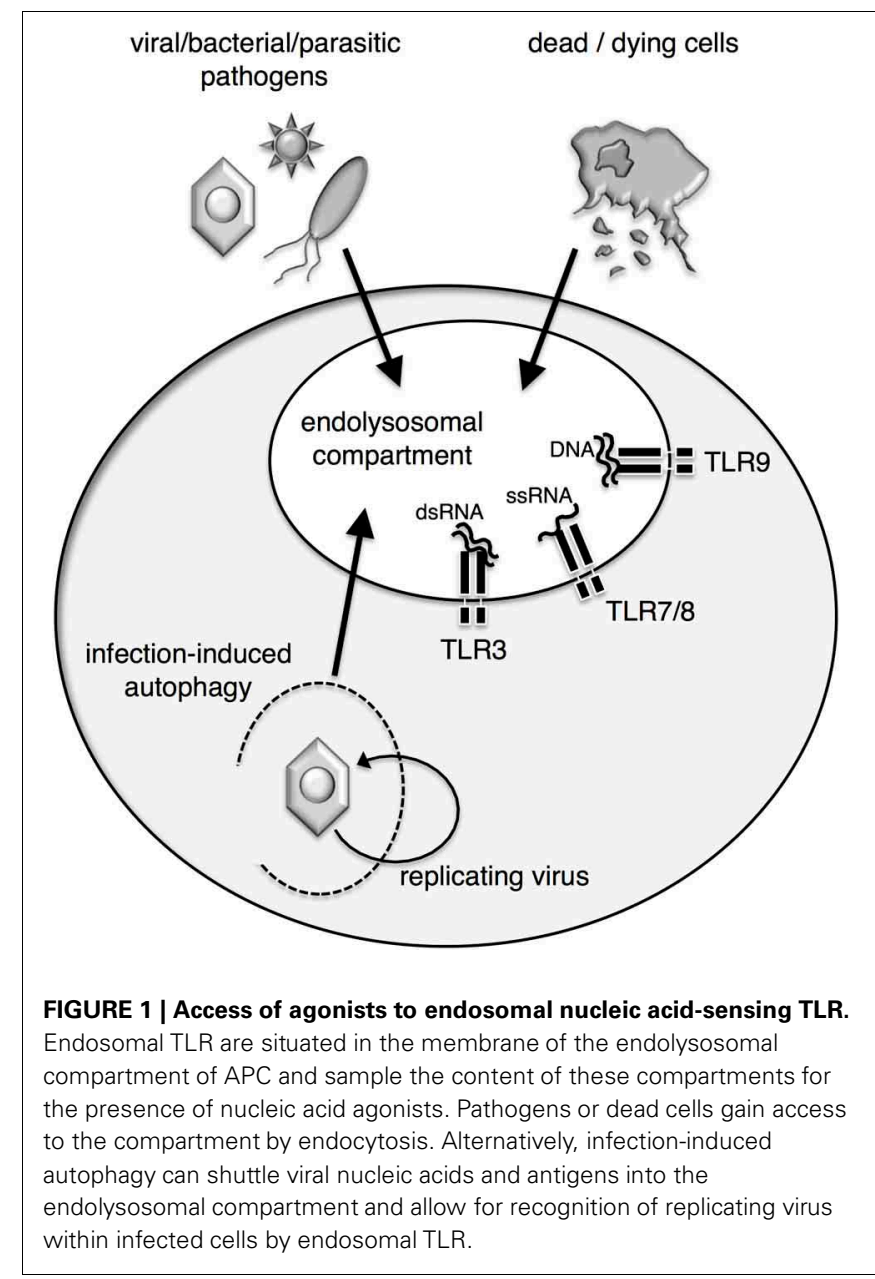

intermediates present in virus-infected cells (Alexopoulou et al., 2001; Schulz et al., 2005). Genomic nucleic acid material from dsRNA viruses such as reoviruses and dsRNA replication intermediates as produced for example by alphaviruses consist of long stretches of dsRNA which represent molecular structures that are absent from uninfected eukaryotic cells. Only short structures of dsRNA are found among cellular RNA such as in the secondary clover-leaf structure of transfer RNA (tRNA) or in microRNA (miRNA). As such, viral dsRNA represents a bona fide PAMP that allows the immune system to distinguish between viral and self RNA molecules. A minimum length of 45 base pairs (bp) is thought to be required for binding to TLR3, but dsRNA molecules $>90$ bp show stronger induction of pro-inflammatory cytokines (Leonard et al., 2008; Liu et al., 2008; Jelinek et al., 2011). Surprisingly, 21 nucleotide-long small interfering RNA (siRNA) molecules have been reported to trigger TLR3-mediated activation in vitro and in vivo contradicting the requirement for dsRNA stretches longer than 45 bp (Kariko et al., 2004a,b; Kleinman et al., 2008). However, other reports failed to detect innate immune activation by siRNA molecules and, furthermore, miRNA and endogenously expressed hairpin siRNA (shRNA) are not immunogenic. These findings suggest that innate immune activation in response to siRNA may represent an experimental 
artifact possibly due to the formation of higher order structures by siRNA preparations. Similarly, messenger RNA (mRNA) was reported to induce TLR3 activation in experimental settings which may be a consequence of using highly pure mRNA preparations devoid of RNA-binding proteins allowing for the formation of higher order structures (Kariko et al., 2004c). Interestingly, functional TLR3 has been detected at the cell surface rather than in endosomes in human fibroblasts (Matsumoto et al., 2003). While the role of TLR3 at the cell surface of fibroblasts is entirely enigmatic, cell surface expression of this particular dsRNA-sensing PRR may not pose an increased risk with regard to autoimmunity induction, since dsRNA represents a bona fide PAMP absent from mammalian cells.

In contrast to TLR3, the other endosomal TLR namely TLR7, TLR8, and TLR9 are unable to distinguish between pathogen and self-nucleic acids on the basis of distinct molecular structures (Barbalat et al., 2011). Mouse TLR7 and human TLR7 and TLR8 serve as PRR for single-stranded RNA (ssRNA), whereas the functionality of mouse TLR8 is still somewhat obscure (Alexopoulou et al., 2012). In addition to viral ssRNA and synthetic uridineor uridine/guanosine-rich oligoribonucleotides (ORN), there is a number of small immune modifiers developed by pharmaceutical companies with TLR7 and/or TLR8-stimulating activity such as the imidazoquinolines R848 and R837 (Smits et al., 2008). $\mathrm{R} 837$ is approved for topical application and is used for treatment of genital warts and basal cell carcinoma because of its TLR-mediated anti-viral and anti-tumouricidal activities, respectively (Wagstaff and Perry, 2007). When RNA was first discovered as the natural agonist of TLR7 and human TLR8, it was immediately obvious that the preference for guanosine/uridine (GU)-rich and uridine (U)-rich sequences by human and mouse ssRNA-sensing TLR, respectively, did not constitute a suitable basis for discrimination between pathogen-associated and selfnucleic acids (Diebold et al., 2004; Heil et al., 2004). Furthermore, mouse TLR7 was demonstrated to respond to ORN corresponding to eukaryotic mRNA sequences and purified mouse mRNA, showing that self-nucleic acid is immunostimulatory when delivered efficiently into the TLR7-sensing endosomal compartment (Diebold et al., 2004, 2006). Interestingly, mammalian RNA contains a high frequency of modifications such as methylated nucleosides or pseudouridines, which ablate TLR7 and TLR8 activation (Kariko et al., 2005). Such modifications are particularly abundant in mammalian tRNA and ribosomal RNA (rRNA) but less frequent in mammalian mRNA (Soll, 1971; Maden and Hughes, 1997). This could explain why total mammalian RNA, which contains a high percentage of RNA species with TLR-inhibitory modifications is not immunostimulatory whereas purified mammalian mRNA when delivered to the endosome in form of complexes with polycations such as polyethylenimine triggers TLR7-dependent innate immune activation (Koski et al., 2004; Kariko et al., 2005; Diebold et al., 2006). Further evidence that TLR7 and human TLR8 cannot discriminate between self and pathogen RNA on the basis of structural differences stems from findings that implicate a central role for the recognition of self RNA in the immunopathogenesis of autoimmune diseases such as systemic lupus erythematosus (SLE), psoriasis, rheumatoid arthritis, Sjörgen's syndrome and others (Theofilopoulos et al.,
2011). Similarly, genetic modifications that lead to a duplication of the TLR7 gene or over-expression of transgenic TLR7 are associated with exacerbated lupus-like symptoms in murine models (Pisitkun et al., 2006; Deane et al., 2007). It is worth noting that TLR7 is located on the X chromosome and that females induce higher levels of IFN-I in response to TLR7 agonists (Berghofer et al., 2006), which could represent a major factor responsible for the higher prevalence of SLE in women.

A similar link to autoimmunity induction has been identified for TLR9 (Theofilopoulos et al., 2011). TLR9 has evolved as innate immune sensor for viral, bacterial, fungal and protozoan DNA and is also activated by synthetic oligodesoxyribonucleotides (ODN) with a phosphorothioate backbone and an unmethylated CpG motif (Bauer et al., 2001; Lund et al., 2003; Parroche et al., 2007; Nakamura et al., 2008). Since the immunostimulatory activity of ODN is dependent on the presence of an unmethylated CpG motif and since such motifs are more abundant in bacterial DNA than in mammalian DNA, it was thought for a long time that TLR9 is able to discriminate between pathogen and self DNA (Hemmi et al., 2000). However, further studies have questioned the requirement for a CpG motif for TLR9-mediated activation (Yasuda et al., 2006; Haas et al., 2008; Wagner, 2008). Using synthetic TLR9 agonists, it was discovered that phosphorothioate ODN have a much higher affinity to TLR9 than ODN with a natural phosphodiester backbone and that the latter exert TLR9 stimulatory activity independent of the presence of CpG motives (Haas et al., 2008). In direct contrast to this, when studying the activation of autoreactive B cells it became apparent that TLR9 stimulation is dependent not only on the presence of CpG motifs in mammalian DNA, but also on the hypomethylated status of the self-nucleic acids (Viglianti et al., 2003). While it is currently unclear how these conflicting results regarding the requirement for unmethylated CpG motives can be reconciled, it is evident that self DNA has the ability to induce TLR9 activation if it enters the endosomal compartment in which recognition takes place.

\section{HOW DOES THE IMMUNE SYSTEM DISCRIMINATE BETWEEN PATHOGEN AND SELF NUCLEIC ACIDS?}

Once it became obvious that the nucleic acid structures recognized by TLR7, TLR8, and TLR9 do not constitute bona fide PAMP and that self-nucleic acids can trigger innate immune activation via these PRR under certain conditions, it was hypothesized that the endosomal localization of these TLR prevents activation by self-agonists under physiological conditions by refusing self-nucleic acids access to the compartment (Diebold et al., 2004; Heil et al., 2004; Barton et al., 2006; Barton and Kagan, 2009). According to this hypothesis, mechanisms that regulate the uptake of material containing pathogen vs. self-nucleic acids must be in place to prohibit innate immune activation in response to the latter.

In this context it is worth remembering that experimental systems often fail to mimic natural processes in all details with regard to innate immune activation by PAMP. In experimental systems, agonists for endosomal TLR such as CpG ODN, R848 and polyI:C for TLR9, TLR7/8, and TLR3 activation, respectively, are administrated in solution whereas ORN for stimulation of TLR7/8 are applied in form of complexes with polycations or cationic lipids 
such as polyethylenimine or DOTAP. In contrast, the natural agonists for endosomal TLR are an integral part of pathogens including viruses or virus-infected host cells and as such are not directly accessible for receptor binding neither at the cell surface nor in the endolysosomal compartment. Consequently, pathogenand host cell-derived material associated with pathogen nucleic acids have to be taken up into the endolysosomal compartment, where degradation allows the nucleic acids to become available for TLR binding. Thus, synthetic mimics of viral nucleic acids added directly to cells in vitro or used as adjuvants in vivo in mouse models are unsuitable to investigate mechanisms that allow the immune system to distinguish pathogen from self-nucleic acids.

Nevertheless, "naked" pathogen-derived and self-nucleic acids may be present in the extracellular space upon release from damaged microbes or disintegrating infected and uninfected host cells. Under physiological conditions, however, natural "naked" nucleic acids are degraded by extracellular DNases and RNases before they can access the endolysosomal compartment. Where such degradation is defective, the danger emanating from released self DNA becomes evident as seen in SLE patients carrying mutations in DNase I and in DNase I-deficient mice, which develop a lupus-like disease (Napirei et al., 2000; Yasutomo et al., 2001). Interestingly, receptors for the uptake of nucleic acids such as scavenger receptors and C-type lectin receptors (CLR) have been described and seem to play a role in the uptake of synthetic nucleic acid TLR agonists such as CpG ODN and polyI:C (Zhu et al., 2001; Limmon et al., 2008; Lahoud et al., 2012). However, synthetic nucleic acid TLR agonists with a phosphorothioate backbone and dsRNA homopolymers as commonly used for experimental TLR activation are more resistant to enzymatic degradation than natural nucleic acids and a relevant role of nucleic acid-binding scavenger receptors in delivering natural nucleic acids into the TLR-sensing endolysosomal compartment under non-pathological conditions is highly questionable. Thus, in order to understand how pathogen-associated nucleic acids gain access to the TLR-sensing endolysosomal compartment while self-nucleic acids are excluded from entering, it is necessary to take into account which pathways are involved in uptake of pathogens and dead cell material.

\section{HOW IS THE UPTAKE OF PATHOGENS AND DEAD CELL MATERIAL MEDIATED?}

Since nucleic acids are typically not available at the surface of pathogens, they are unlikely to play a role in pathogen uptake. Furthermore, it has been shown that uptake of TLR agonists is independent of TLR9, even in soluble form such as CpG ODN. During infections, cells of the innate immune system internalize pathogens for sampling by endosomal TLR by a number of different ways: (1) by receptor-mediated endocytosis in response to binding to scavenger receptors, (2) by phagocytosis which is promoted by the complement system through opsonisation, and (3) by Fc receptor (FcR)-mediated uptake upon opsonisation with antibodies (Figure 2). Similarly, material from infected and uninfected dead cells is taken up by specialized cell types such as macrophages and DC involving scavenger receptor-, complement- and antibody-mediated uptake (Figure 2).

\section{SCAVENGER RECEPTOR-MEDIATED UPTAKE}

Uptake of pathogens and pathogen-derived material is mediated by scavenger receptors that are expressed among other cell types by phagocytic macrophages and antigen-presenting DC. Scavenger receptors encompass a group of structurally unrelated transmembrane surface molecules with relatively promiscuous ligand binding characteristics such as scavenger receptor A (SR-A), MARCO and CD36. This promiscuity allows scavenger receptors to mediate uptake of a wide range of pathogens including gram-positive and gram-negative bacteria, yeast, viruses and parasites (Mukhopadhyay and Gordon, 2004). However, due to the observed redundancy and the promiscuous and overlapping ligand-binding characteristics of scavenger receptors, little is known about their natural ligands and the structural basis for ligand binding. Interestingly, scavenger receptors are also involved in the uptake of dead cell material by both macrophages and DC (Peiser et al., 2002; Harshyne et al., 2003; Parlato et al., 2010). In case of macrophages, clearance of dead cells is involved in re-establishment of tissue homeostasis whereas DC ingest cellular material to instruct and regulate $\mathrm{T}$ cell responses against cellular and cell-associated antigens. Due to these functional differences, the uptake of pathogens and dead cell material differs quantitatively between macrophages and DC. In addition, qualitative differences in the pathways that mediate uptake by these antigen-presenting cell types also exist. For example, it has been shown that, unlike macrophages, DC acquire cell-associated antigen from live cells via a SR-A-dependent uptake mechanisms (Harshyne et al., 2003). However, the composition of the cellular material ingested by DC through "nibbling" on live cells is unknown and it would be interesting to determine whether cellular nucleic acids are present in the cellular material that is taken up or whether specific species of cellular nucleic acids are excluded.

In macrophages, the scavenger receptors MARCO and SR-A are involved in uptake of CpG ODN and influence TLR9mediated IL-12 induction with MARCO enhancing and SR-A reducing its production (Jozefowski et al., 2006). Interestingly, the binding to SR-A is dependent on the presence of serum, suggesting that CpG ODN may have to be available in form of complexes with nucleic acid-binding proteins in order to bind SR-A (Jozefowski et al., 2006). Similarly, the serum factor granulin or its precursor pro-granulin binds to CpG ODN and mediates uptake into the endolysosomal compartment probably by a sortilin-dependent pathway (Park et al., 2011). Macrophages from MARCO and SR-A deficient mice show the same opposing alterations in IL-12 induction in response to the TLR4 agonist lipopolysaccharide suggesting that the modulation of TLR activation by scavenger receptors is not restricted to endosomal nucleic acid-sensing TLR (Jozefowski et al., 2005).

\section{COMPLEMENT-MEDIATED PHAGOCYTOSIS}

In addition to scavenger receptor-mediated uptake, pathogens and dead cell material can be ingested via complement receptormediated uptake upon opsonisation with complement factors. In contrast to live cells, which have the ability to actively remove deposits of the complement cascade on their cell surface, dead cells and pathogens are unable to do so and become opsonised by complement factors (Trouw et al., 2008). For example, the 


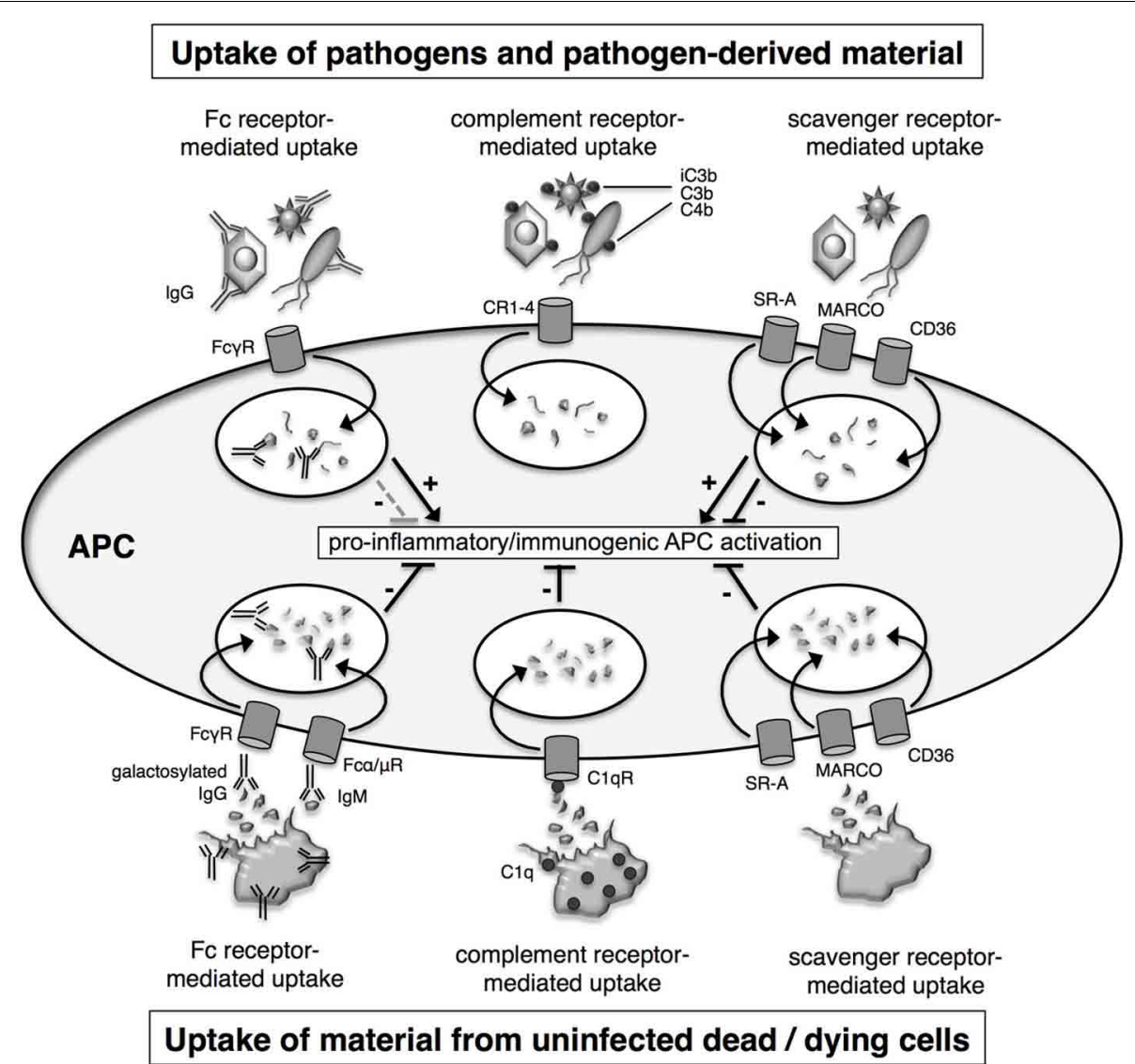

FIGURE 2 | Mechanisms for uptake of pathogens and dead cells. Material from pathogens and dead cells is taken up via the same uptake mechanisms, which include Fc receptor-, complement receptor- and scavenger receptor-mediated uptake. Fc receptor- and complement receptor-mediated uptake require the prior opsonisation of the cargo with antibodies and complement factors, respectively. APC activation is tightly regulated and influenced both by the source of the material and uptake route. Uptake of material from dying uninfected cells induces a number of regulatory pathways which attenuate pro-inflammatory immunogenic antigen-presenting cells (APC) activation. In contrast, uptake of pathogens or pathogen-derived material as associated with infected dying cells leads to pro-inflammatory immunogenic activation of APC. complement component C1q binds to antibodies complexed with antigen. This includes IgG and IgM antibodies bound to soluble antigens, pathogens and dead cells. Interestingly, $\mathrm{Clq}$ has also been shown to bind DNA and RNA, which is exposed on the surface of dying cells in late apoptosis and is involved in the degradation of DNA in cooperation with DNase I (Gaipl et al., 2004; Palaniyar et al., 2004). Thus, binding and removal of cellular DNA from dead cells by C1q presents one mechanism that prevents the activation of the innate immune system by self-nucleic acids. Furthermore, $\mathrm{Clq}$ inhibits $\mathrm{NF}$ B B activation in response to TLR stimulation, reducing the induction of pro-inflammatory cytokines by monocytes, macrophages and DC (Fraser et al., 2009). The important regulatory role of C1q in preventing innate immune activation by dead cells accumulating in the tissue is underpinned by the finding that C1q deficiency leads to autoimmunity induction in humans and mice resulting in SLE and SLE-like symptoms, respectively (Schur, 1977; Botto et al., 1998). Defects in other proteins that are involved in the removal of cell remains such as mutations in serum amyloid $\mathrm{P}$, milk fat globule-epidermal growth factor 8 and TAM receptor protein tyrosinase kinase family also lead to lupus-like syndromes (Bickerstaff et al., 1999; Paul and Carroll, 1999; Lu and Lemke, 2001; Hanayama et al., 2004). Interestingly, not all defects in complement proteins participating in the removal of dead cells from the tissue lead automatically to SLE-like symptoms, since deficiencies in other complement components such as Mannanbinding lectin (MBL) and C3 affect uptake of dead cells but do not promote autoimmunity induction (Takizawa et al., 1996; Sekine et al., 2001; Stuart et al., 2005). Taken together, these findings support the hypothesis that the ability of C1q to instigate DNA degradation and to regulate TLR-mediated NFKB activation may represent characteristics of $\mathrm{Clq}$ function that are crucial for the prevention of endosomal TLR activation by self-nucleic acids and autoimmunity induction.

\section{FCR-MEDIATED UPTAKE}

Similar to opsonisation with complement, pathogens can be opsonised with antibodies mediating uptake via FcR on macrophages and DC. As for receptor- and complementmediated uptake, antibody-mediated uptake is not restricted to 
pathogens and is also observed for dead cells. In particular, IgM was shown to bind to oxidation-specific epitopes exposed on late apoptotic cells (Chang et al., 1999). Interestingly, IgM-mediated uptake of apoptotic cells via $\mathrm{F} c \alpha / \mu \mathrm{R}$ down-modulates inflammatory responses by regulating APC activation and inhibits inflammatory and autoimmune diseases such as arthritis and SLE, respectively (Kim et al., 2003; Chen et al., 2009b; Jiang et al., 2011; Notley et al., 2011). Opsonisation with IgG and uptake by Fcy receptor $(\mathrm{Fc} \gamma \mathrm{R})$ can either promote or down-modulate activation of antigen-presenting cells depending on which Fc $\gamma \mathrm{R}$ family members mediates uptake. Independent of activation, antigen presentation is much more efficient for antigens taken up in form of immune complexes via $\mathrm{Fc} \gamma \mathrm{R}$ than for antigens ingested by pinocytosis (Ivan and Colovai, 2006).

In addition to promoting uptake of pathogens and dead cells through opsonisation, antibodies bound to antigen also trigger the complement cascade and thus promote the killing of pathogens and advance the phagocytosis of pathogens and dead cells through further opsonisation with complement factors creating a potent feedback loop.

\section{DIFFERENCES IN INGESTING PATHOGENS vs. DEAD CELL MATERIAL}

None of the discussed uptake mechanisms for pathogens differ fundamentally from those mediating uptake of dead cells. While C1q- and IgM-mediated uptake of apoptotic cells is associated with induction of regulatory pathways and crucial for preventing autoimmunity induction, their binding to dead cells is not exclusive and they play an equally important role in uptake of pathogens. This seems entirely reasonable since both dead cells and pathogens represent entities that have to be removed in order to restore tissue homeostasis. However, the hazards emanating from uninfected dead cells are very different from those associated with pathogens and infected dying cells and the immune system has to be able to distinguish the two scenarios in order to prevent autoimmunity induction. The discrimination between pathogen and cellular nucleic acids is most crucial for APC with the capacity to prime or promote antigen-specific $\mathrm{T}$ cell responses in response to activation via nucleic acid sensing TLR.

\section{AND THE DISCRIMINATION BETWEEN PATHOGEN AND SELF NUCLEIC ACIDS}

PDC and specific DC subsets specialized in cross-priming of viral antigen-specific CD8 $\mathrm{T}$ cells seem to play particular but distinct roles during virus infections (Belz et al., 2009). PDC are a cell type specialized in virus recognition via TLR7 and TLR9 (Bao and Liu, 2013). They produce high systemic levels of IFN-I upon recognition of viral ssRNA or viral DNA and are, therefore, also known as natural IFN-producing cells (Bao and Liu, 2013). High levels of systemic IFN-I are a hallmark of viral infection and influence the anti-viral immune response on many levels (Levy et al., 2011). IFN-I drives the differentiation of monocytes into inflammatory DC, promotes the T cell stimulatory activity of APC, supports $\mathrm{T}$ helper cell-independent class switching of $\mathrm{B}$ cells, skews the $\mathrm{T}$ helper response toward a Th1 phenotype and aids the induction of cytotoxic T lymphocyte (CTL) responses by directly acting on CD8 T cells (Le Bon and Tough, 2008). However, IFN-I production in response to virus infection is not necessarily dependent on PDC (Swiecki and Colonna, 2010). While it is accepted that PDC are specialized in virus recognition and IFN-I production, the role of PDC as antigen-presenting cells during virus infection is less well understood. There are conflicting results on their endocytic activity and their ability to present exogenous antigens and it is evident that PDC differ from other DC subsets with regard to the uptake and processing of exogenous antigens (Villadangos and Young, 2008). However, PDC clearly take up virus particles. Viruses such as influenza virus enter PDC via receptor-mediated uptake into the TLR-sensing endolysosomal compartment, which is their natural infection route (Patterson et al., 1979; Londrigan et al., 2012). In contrast, fusogenic viruses such as Coxsackie virus and foot-and-mouse-disease virus are dependent on the presence of anti-viral antibodies and complex formation for uptake into endosomes via Fc $\gamma \mathrm{R}$ expressed by PDC (Guzylack-Piriou et al., 2006; Wang et al., 2007). In addition to the recognition of genomic viral material, PDC can become activated by viral ssRNA replication intermediates, which accumulate in the cytoplasm upon infection and are then shuttled into the endolysosomal compartment for recognition by TLR7 by autophagy (Lee et al., 2007). The initiation of virus-induced autophagy is driven by cytoplasmic PRR and hence cytoplasmic self-nucleic acids are not subject of translocation to the endolysosomal compartment in uninfected cells (Tal and Iwasaki, 2009). Thus, under physiological conditions, PDC usually do not encounter cellular nucleic acids making a distinction between self-versus pathogen nucleic acid dispensable for this cell type. However, once the regulatory mechanism that prevent the release and accumulation of nucleic acids from dead cells fail and allow for complex formation of cellular RNA and DNA with antibodies or the antimicrobial peptide LL37, PDC become a driving force for autoimmune induction as observed in SLE and psoriasis, respectively (Lovgren et al., 2004; Barrat et al., 2005; Lande et al., 2007; Ganguly et al., 2009).

Specific DC subsets such as mouse CD8 $\alpha^{+} \mathrm{DC}$, the related $\mathrm{CD}_{103}{ }^{+} \mathrm{DC}$ and human $\mathrm{BDCA}^{+} \mathrm{DC}$ are specialized in the uptake of cellular material from dying cells and cross-present cell-associated antigen to CD8 T cells. While immature CD8 $\alpha$ like DC are involved in peripheral tolerance induction, activated CD8 $\alpha$-like DC prime CTL responses against cell-associated antigens and thereby play a crucial role in anti-viral immunity (Joffre et al., 2012). The cellular material that is taken up by this specialized DC subset is sampled in the endolysosomal compartment in which TLR activation takes place. CD8 $\alpha$-like DC express TLR3 and TLR8 and, therefore, can detect viral dsRNA and theoretically also ssRNA associated with virus-infected cells (Schulz et al., 2005). It is still entirely unclear how CD8 $\alpha$-like DC avoid the activation by cellular RNA. The presence of gatekeeper receptors with the ability to control or modulate the recruitment of nucleic acid-sensing TLR to the endolysosomal compartment of CD8 $\alpha$-like DC could play a role in avoiding the activation of these cells in response to self-nucleic acids from uninfected dying cells. The recruitment of nucleic acid-sensing TLR to the endolysosomal compartment could be initiated by gatekeeper receptors upon sensing of non-nucleic acid PAMP or damage-associated molecular patterns (DAMP) present in infected cells but absent from uninfected cells (Figure 3B). Alternatively, CD8 $\alpha$-like DC may be very selective regarding the cellular material that they 


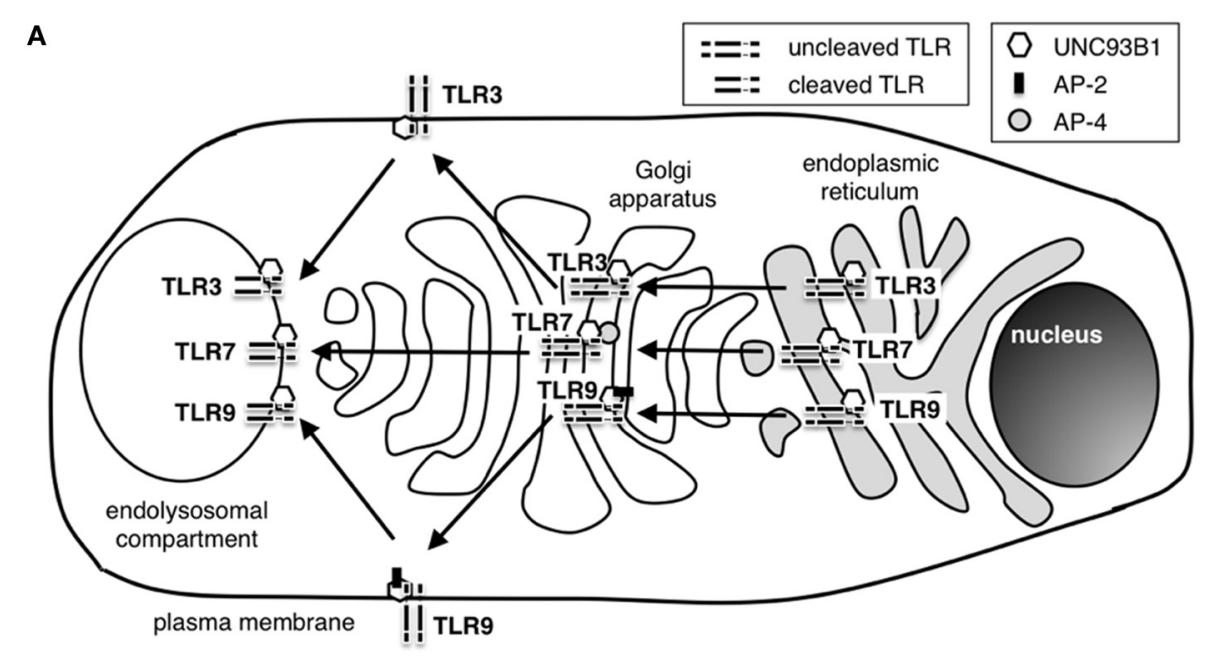

B

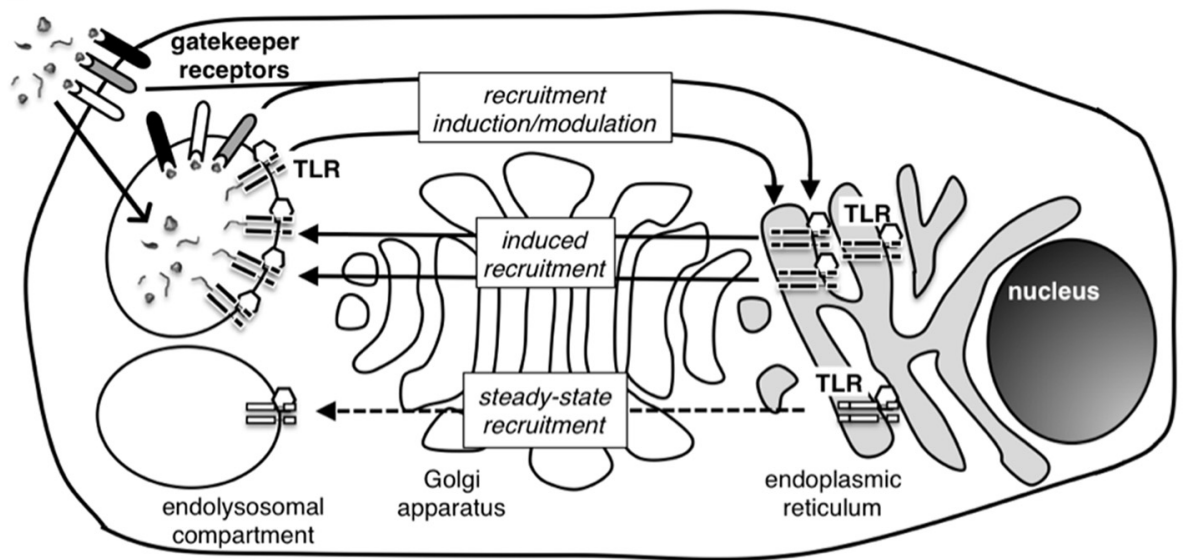

FIGURE 3 | How are nucleic acid-sensing TLR recruited to the endolysosomal compartment? (A) Nucleic acid sensing TLR traffic to the endolysosomal compartment from the endoplasmic reticulum (ER) via the Golgi apparatus. The chaperone protein UNC93B1 is necessary for successful migration of all three endosomal TLR, and adaptor protein (AP) complexes AP-2 an AP-4 are additionally required during the shuttle process of TLR9 and TLR7, respectively. TLR9, but not TLR7, is transiently located at the cell plasma membrane before reaching the endolysosome. Similarly, TLR3 has been detected at the cell surface in specific cell types. The reason for these differences in trafficking pathways for endosomal TLR is currently unknown. While in the ER and passing through the Golgi, TLR remain in an uncleaved state and only undergo cleavage to attain functional activation after arrival in the endolysosome. The requirement for cleavage is thought to be a protective mechanism to avoid unwanted TLR activation outside the endolysosomal compartment. (B) The induction and regulation of TLR recruitment to the endolysosomal compartment is still poorly understood. A small number of TLR have been detected in the endolysosomal compartment in the absence of activating stimuli suggesting the presence of a self-perpetuating low-frequency shuttling process of TLR to the endolysosome (steady-state recruitment). During infection, high frequency recruitment of TLR to the endolysosome takes place (induced recruitment). Induced recruitment is likely to be initiated by PAMP-activated TLR and/or other PRR. However, gatekeeper receptors controlling pathways such as the CD24-Siglec or CLR-Syk pathway have the ability to modulate and maybe even induce TLR recruitment to the endolysosomal compartment. The presence of gatekeeper receptors with the ability to distinguish specific signals from pathogens or uninfected host cells and to promote or regulate TLR recruitment is likely to play an important role in protecting the host from innate autoimmune activation. ingest in order to reduce the uptake of self-nucleic acids. Mouse CD $8 \alpha^{+}$DC and human monocyte-derived DC have been shown to "nibble" on apoptotic cells rather than ingesting whole cells (Schulz and Reis E Sousa, 2002; Harshyne et al., 2003). It is currently unclear what cellular components are present in the cellular fragments that are taken up by CD8 $\alpha$-like DC. By restricting the endocytosed material to membrane fragments, it may be possible for CD8 $\alpha$-like DC to favor uptake of viral components that associate with the plasma membrane as part of virus assembly and/or viral budding processes and to avoid uptake of cellular nucleic acids. A better understanding of the mechanisms underlying the uptake of cellular material by CD8 $\alpha$-like DC could provide vital insight into how discrimination between viral and self-nucleic acids is achieved by these specialized APC.

\section{WHAT MECHANISMS AID IN THE DISCRIMINATION BETWEEN VIRAL AND CELLULAR NUCLEIC ACIDS?}

Since the uptake of pathogens and dead cells is not fundamentally different, it is very likely that additional mechanisms have to be in place to favor the recognition of viral nucleic acids and prevent the 
recognition of self-nucleic acids. Mechanisms that would allow the innate immune system to discriminate between self and viral nucleic acids could be based on the following characteristics: (1) as discussed above total cellular nucleic acids contain enough modified RNA species such as tRNA and rRNA which inhibit the activation of endosomal TLR in the presence of stimulatory selfnucleic acid such as mRNA; (2) sequestration of cellular nucleic acids through binding to cellular components may prevent binding to endosomal TLR and/or (3) the recruitment of nucleic acid-sensing TLR to the endolysosomal compartment or their functional activation by cleavage may be regulated by gatekeeper molecules sensing PAMP and/or DAMP absent from uninfected dead cells or DAMP absent from infected dead cells. The evidence for and the implications of the existence of these mechanisms and their involvement in the discrimination between pathogen and self-nucleic acids are discussed below.

(1) Modified cellular nucleic acids clearly can inhibit endosomal TLR activation by self-nucleic acids as discussed earlier (Kariko et al., 2005). However, it is less clear how TLR activation by viral nucleic acids upon uptake of material from infected cells is possible in the presence of modified cellular nucleic acids. It is unclear whether or not viral nucleic acid species associated with material from infected cells directly compete with cellular nucleic acids including modified nucleic acid species for binding to endosomal TLR. If this is the case, virus-derived nucleic acids have to be present in relative excess to trigger a response. The ratio between viral and cellular nucleic acids present inside infected cells is highly variable between viruses. While little is known about quantitative and qualitative differences in binding of viral vs. cellular nucleic acids to TLR, relative binding of RNA to polyribosomes in infected cells has been quantified. Quantitative analysis of viral vs. cellular RNA for Semiliki forest virus, herpes simplex virus and moloney murine leukaemia virus excluded direct competition as a means for preferential translation of viral RNA in infected cells (Tuomi et al., 1975; Stringer et al., 1977; Guttman-Bass et al., 1980). Thus, it is unlikely that direct competition between viral and cellular RNA in infected cells forms the general basis for preferential recognition of viral RNA associated with infected cells by endosomal TLR.

(2) One example for sequestration of cellular DNA in dying cells is high-mobility group protein B1 (HMGB1). HMGB1 binds to DNA and interacts with nucleosomes, transcription factors and histones. During early apoptosis HMGB1 binds tightly to chromatin within the dying cell as a consequence of underacetylation and, thereby, prevents the release of HMGB1 and cellular DNA even after the cells undergo secondary necrosis (Scaffidi et al., 2002) (Figure 4). Thus, HMGB1 represents a prime example for a molecule sequestering cellular nucleic acids in order to prevent unwanted inflammation and immune responses in response to cell death in the absence of infection.

However, HMGB1 also plays multiple roles in influencing the induction of immune responses mediated through a number of different receptors it can bind to. Upon release, HMGB1 can signal through TLR2, TLR4, the receptor for advanced glycation endproducts (RAGE), CD24, Thrombin and CXCR4 (Yanai et al., 2012). HMGB1 is released by monocytes, macrophages and DC in response to TLR stimulation (Dumitriu et al., 2005). Autocrine/paracrine HMGB1 plays a crucial role in DC mobilization. Binding of HMGB1 to RAGE on DC controls the homing of activated DC to the draining lymph node (Manfredi et al.,

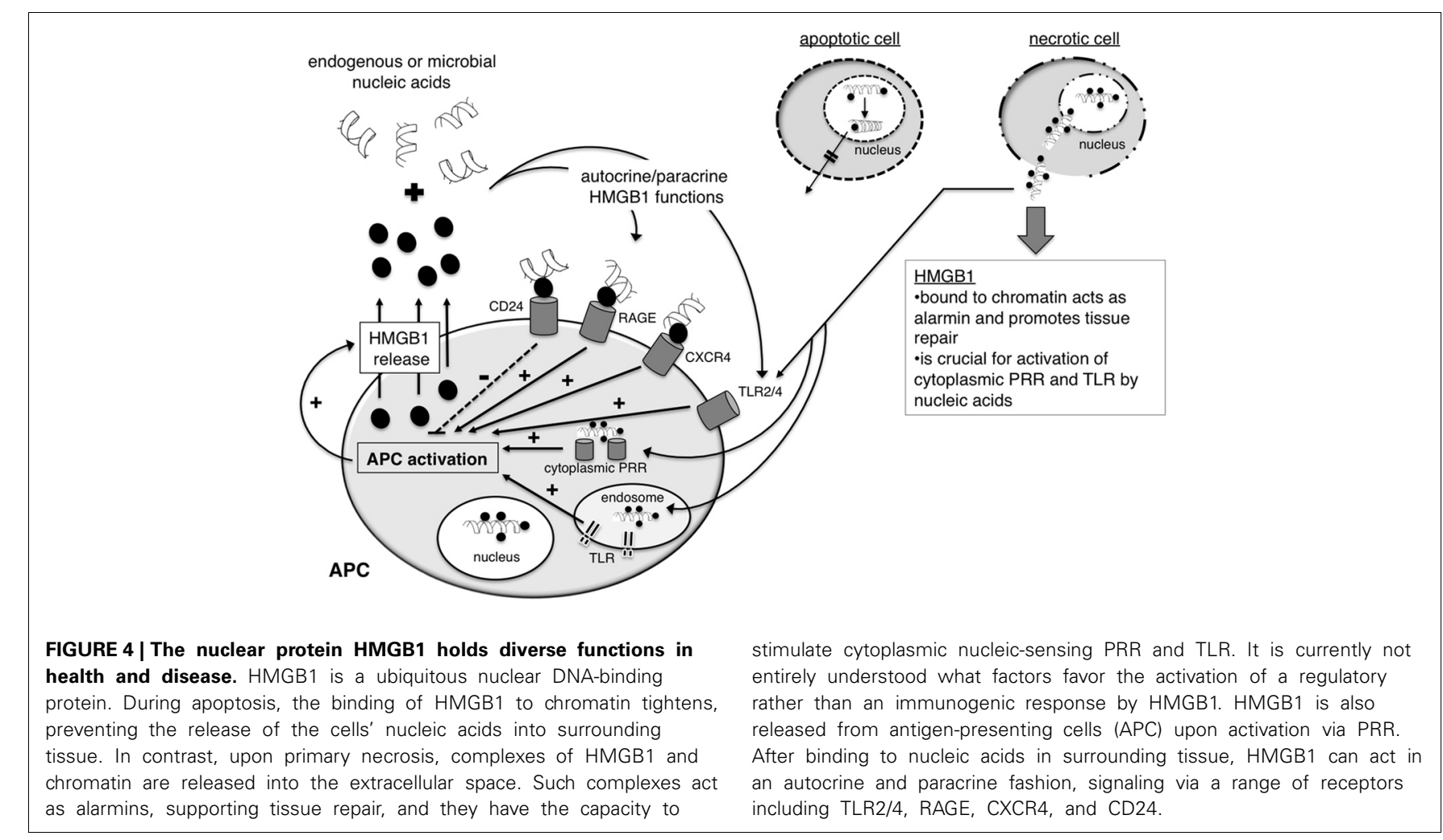


2008). Interestingly, engagement of RAGE by HMGB1 also promotes the induction of IFN-I by PDC in response to CpG ODN (Tian et al., 2007). However, as observed for TLR9, the binding of ODN to HMGB1 seems to be affected by the sugar backbone with natural phosphodiester ODN showing little binding in contrast to artificial phopshorothioate ODN. Furthermore, HMGB proteins have been described as universal sentinels for nucleic acids, since HMGB1-3 bind different nucleic acid species and promote the activation of cytoplasmic and endosomal nucleic acid-sensing PRR (Yanai et al., 2009). The activation of cytoplasmic and endosomal nucleic acid-sensing PRR is severely impaired in the absence of HMGB proteins and the authors, therefore, postulated that binding of RNA and DNA to HMGB proteins may be a general prerequisite for activation of nucleic acid-sensing PRR. Alternatively, nucleic acid-binding to HMGB proteins may support ligand recognition by preventing nucleic acid degradation. In this context, it is interesting to note that DC release HMGB1 upon activation and thereby may aid the recognition of viral nucleic acids in an inflammatory context (Dumitriu et al., 2005).

The seemingly opposing roles of HMGB1 in protecting innate immune activation in response to cellular DNA and promoting DC activation upon secretion in response to TLR stimulation are difficult to reconcile. Furthermore, since neither HMGB1 nor the ssRNA- and DNA-sensing TLR are able to discriminate between pathogen-derived and self-nucleic acids, the promotion of endosomal TLR activation by nucleic acids bound to HMGB proteins has the potential for disastrous consequences with regard to autoimmunity induction. In support of this notion are the findings that elevated expression levels of HMGB1 have been detected in serum and in kidney of SLE patients, suggesting that HMGB1 plays a role in autoimmune pathology (Jiang and Pisetsky, 2008; Qing et al., 2008). Thus, the release of stimulatory nucleic acid-HMGB1 complexes from necrotic cells may have to be regarded as a pathological situation. However, a physiological role for such complexes cannot be entirely excluded and it was argued that these complexes represent an alarmin with the capacity to promote repair in damaged tissue (Yang et al., 2007a). Interestingly, HMGB1 also binds to CD24, which triggers the regulatory Siglec G pathway and, thereby, suppresses immune activation in response to HMGB1-TLR4 signaling (Chen et al., 2009a). While the CD24-Siglec pathway protects the host from responding to pathological cell death, responses to PAMP are unaffected by this pathway. As such, the CD24-Siglec pathway may represent one example for a pathway with gatekeeper function that allows the immune system to discriminate between endogenous alarmins vs. pathogen-derived PAMP.

(3) Gatekeeper receptors with the ability to detect PAMP and/or DAMP absent from uninfected cells are involved in the recruitment or the cleavage of nucleic acid-sensing TLR to the endolysosomal compartment would represent an additional powerful mechanism for preventing the recognition of self-nucleic acids upon uptake of cellular material from uninfected cells (Figure 3B). While it is established that nucleic acid-sensing TLR have to be recruited to the endolysosomal compartment upon uptake of pathogens or cellular material, the exact mechanisms of the recruitment remain unexplored. Initially, it was thought that TLR9 is located in the ER in unstimulated cells and is recruited to the endolysosomal compartment only after uptake of TLR9 agonist (Latz et al., 2004). More recent findings indicate that low level of trafficking of nucleic acid-sensing TLR via the Golgi to the endolysosomal compartment takes place in the steady state and that these few TLR molecules may initiate TLR recruitment upon stimulation with nucleic acids (Ewald et al., 2008; Park et al., 2008; Chockalingam et al., 2009; Blasius and Beutler, 2010). This model is supported by the finding that transgenic TLR-GFP is cleaved and transported to the endolysosomal compartment in unstimulated cells (Avalos et al., 2013). Interestingly, TLR4 activation induces the recruitment of nucleic acid-sensing TLR to the endolysosomal compartment, showing that other pathways can influence TLR-mediated detection of nucleic acids (Kim et al., 2008). Additional evidence that gatekeeper receptors may regulate the recruitment and/or cleavage of endosomal TLR stems from findings demonstrating that $\mathrm{CpG}$ ODN-mediated TLR9-independent activation of the Src family pathway at the cell surface of antigen-presenting cells is crucial for the subsequent activation of NFKB via TLR9 (Sanjuan et al., 2006). This study further indicated the indirect association of TLR9 and Syk downstream of CpG-mediated activation of the Src family pathway. Possible candidates for Syk recruitment include ITAM- and ITIM-containing CLR, which play a role in antigen-processing and -presentation in DC and other myeloid cells (Kerrigan and Brown, 2010). While there is no direct evidence for CLR acting as gatekeeper molecules with the capacity to control the recruitment or the cleavage of nucleic acid-sensing TLR, CLR are known to influence TLR-mediated immune activation of antigen-presenting cells (Dennehy et al., 2008; Ferwerda et al., 2008; Meyer-Wentrup et al., 2009; Xaplanteri et al., 2009; Jahn et al., 2010; Eberle and Dalpke, 2012).

CLR comprise a very heterogeneous family of molecules with a carbohydrate recognition domain, which mediates binding to carbohydrate structures of pathogen- or self-origin (Robinson et al., 2006). The CLR DC-SIGN has been shown to down-modulate activation in response to TLR stimulation via Raf-dependent acetylation of NFKB (Gringhuis et al., 2007). DC-SIGN is a CLR that has evolved to mediate cellular interactions by binding to ICAM-2 and ICAM-3. However, a number of mannoseexpressing pathogens, such as mycobacterium tuberculosis and HIV, bind to DC-SIGN and down-modulate TLR-mediated immune activation to their own advantage. While DC-SIGN clearly has the ability to influence TLR-mediated activation, it is primarily involved in the recognition of self-carbohydrate moieties as part of intercellular interactions. It blunts rather than promotes TLR-mediated activation and is, therefore, an unlikely candidate for initiating the recruitment of TLR to the endolysosomal compartment.

Another pathway with the ability to detect PAMP which has been shown to influence TLR-mediated immune activation is the complement system. The anaphylatoxins C3a and C5a increase NFKB activation and lead to enhanced induction of proinflammatory cytokines such as IL-6 and TNF $\alpha$ in mouse and human DC (Peng et al., 2006, 2008; Lalli et al., 2007; Li et al., 2012). However, regulatory effects of anaphylatoxins have also been described resulting in reduced induction of IL-12, IL-23, and IL-27 (Hawlisch et al., 2005; Lalli et al., 2007). Recently, it was 
shown that $\mathrm{N}$-glycan galactosylation of IgG1 antibody promotes concurrent signaling via the CLR dectin-1 and the inhibitory Fc $\gamma$ RIIB receptor and, thereby, exerts anti-inflammatory influence on C5a-mediated inflammatory responses (Karsten et al., 2012). The frequency of galactosylated serum IgG decreases under pro-inflammatory conditions such as during infection or in autoimmune disease (Karsten et al., 2012). Thus, the regulation of $\mathrm{N}$-glycan galactosylation of IgG seems to represent an additional mechanism to dampen unwanted pro-inflammatory responses in an uninfected host.

The crosstalk between complement and TLR activation is a perfect example for how two independent PRR systems that are triggered by separate sets of PAMP can converge and provide positive feedback for increased innate immune activation. However, it is still poorly understood why complement activation enhances cytokine induction in response to PRR activation in some situations and dampens the response in others. Further insight into the factors that determine under which conditions complement promotes or suppresses TLR-mediated immune activation may lead to a better understanding of how innate immune activation in response to sterile cell death and the release of potentially stimulatory self-nucleic acids is avoided.

\section{CONCLUSION}

In conclusion, we put forward the hypothesis that the sensing of naked ssRNA and DNA, which is not associated with

\section{REFERENCES}

Ahn, J., Gutman, D., Saijo, S., and Barber, G. N. (2012). STING manifests self DNA-dependent inflammatory disease. Proc. Natl. Acad. Sci. U.S.A. 109, 19386-19391. doi: 10.1073/pnas.1215006109

Alexopoulou, L., Desnues, B., and Demaria, O. (2012). [Toll-like receptor 8: the awkward TLR]. Med. Sci. (Paris) 28, 96-102. doi: 10.1051/medsci/2012281023

Alexopoulou, L., Holt, A. C., Medzhitov, R., and Flavell, R. A. (2001). Recognition of doublestranded RNA and activation of NF-kappaB by Toll-like receptor 3. Nature 413, 732-738. doi: $10.1038 / 35099560$

Avalos, A. M., Kirak, O., Oelkers, J. M., Pils, M. C., Kim, Y. M., Ottinger, M., et al. (2013). Cellspecific TLR9 trafficking in primary APCs of transgenic TLR9-GFP mice. J. Immunol. 190, 695-702. doi: 10.4049/jimmunol.1202342

Bao, M., and Liu, Y. J. (2013). Regulation of TLR7/9 signaling in plasmacytoid dendritic cells. Protein Cell 4, 40-52. doi: 10.1007/s13238-012-2104-8

Barbalat, R., Ewald, S. E., Mouchess, M. L., and Barton, G. M. (2011). Nucleic acid recognition by the innate immune system. Аnnu. Rev. Immunol. 29, 185-214. 031210-101340

Barrat, F. J., Meeker, T., Gregorio, J., Chan, J. H., Uematsu, S., Akira, S., et al. (2005). Nucleic acids of mammalian origin can act as endogenous ligands for Tolllike receptors and may promote systemic lupus erythematosus. J. Exp. Med. 202, 1131-1139. doi: 10.1084/jem.20050914

Barton, G. M., and Kagan, J. C. (2009). A cell biological view of Tolllike receptor function: regulation through compartmentalization. Nat. Rev. Immunol. 9, 535-542. doi: 10.1038/nri2587

Barton, G. M., Kagan, J. C., and Medzhitov, R. (2006). Intracellular localization of Toll-like receptor 9 prevents recognition of self DNA but facilitates access to viral DNA. Nat. Immunol. 7, 49-56. doi: 10.1038/ni1280

Bauer, S., Kirschning, C. J., Hacker, H., Redecke, V., Hausmann, S., Akira, S., et al. (2001). Human TLR9 confers responsiveness to bacterial DNA via speciesspecific CpG motif recognition. Proc. Natl. Acad. Sci. U.S.A. 98, 9237-9242. doi: 10.1073/pnas. 161293498

Belz, G., Mount, A., and Masson, F. (2009). Dendritic cells in viral infections. Handb. doi: 10.1146/annurev-immunol-

pathogen-derived material including non-nucleic acid PAMP, represents a precarious feature of the immune system. It doesn't allow for the discrimination between pathogen-associated vs. self-nucleic acids and, therefore, has the potential to lead to autoimmunity. Hence, any mechanisms that allow for or promote the recognition of naked ssRNA and DNA such as in form of immune complexes should be regarded as non-physiological events. Furthermore, we propose that the discrimination between pathogen-derived and self-nucleic acids can be based on at least three separate mechanisms alone or in combination: (1) avoidance of uptake of self-nucleic acids in a form that allows TLR binding, (2) association of self-nucleic acids with cellular components that prevent TLR binding and (3) the presence of gatekeeper receptors, which control the recruitment of TLR to the endolysosomal compartment. Identification of the mechanisms that favor the recognition of pathogen-associated nucleic acids and limit TLR-mediated activation in response to self-nucleic acids will be instrumental for developing more refined strategies to exploit activation of endosomal TLR in the context of vaccines and tumor immunotherapy and for gaining a better understanding of the processes that can lead to autoimmunity induction.

\section{ACKNOWLEDGMENTS}

We thank Claudia Kemper and Caetano Reis e Sousa for helpful discussions and critical review of the manuscript. Eva Brencicova is funded by a Cancer Research UK PhD studentship.

Exp. Pharmacol. 51-77. doi: 10.1007/978-3-540-71029-5_3

Berghofer, B., Frommer, T., Haley, G., Fink, L., Bein, G., and Hackstein, H. (2006). TLR7 ligands induce higher IFN-alpha production in females. J. Immunol. 177, 2088-2096.

Bickerstaff, M. C., Botto, M., Hutchinson, W. L., Herbert, J., Tennent, G. A., Bybee, A., et al. (1999). Serum amyloid P component controls chromatin degradation and prevents antinuclear autoimmunity. Nat. Med. 5, 694-697. doi: 10.1038/9544

Blasius, A. L., and Beutler, B. (2010). Intracellular toll-like receptors. Immunity 32, 305-315. doi: 10.1016/j.immuni.2010.03.012

Botto, M., Dell'agnola, C., Bygrave, A. E., Thompson, E. M., Cook, H. T., Petry, F., et al. (1998). Homozygous Clq deficiency causes glomerulonephritis associated with multiple apoptotic bodies. Nat. Genet. 19, 56-59.

Brinkmann, M. M., Spooner, E., Hoebe, K., Beutler, B., Ploegh, H. L., and Kim, Y. M. (2007). The interaction between the ER membrane protein UNC93B and TLR3 7, and 9 is crucial for TLR signaling. J. Cell Biol. 177, 265-275. doi: 10.1083/jcb. 200612056

Chang, M. K., Bergmark, C., Laurila, A., Horkko, S., Han, K. H.,
Friedman, P., et al. (1999). Monoclonal antibodies against oxidized low-density lipoprotein bind to apoptotic cells and inhibit their phagocytosis by elicited macrophages: evidence that oxidation-specific epitopes mediate macrophage recognition. Proc. Natl. Acad. Sci. U.S.A. 96, 6353-6358. doi: 10.1073/pnas.96.11.6353

Chen, G. Y., Tang, J., Zheng, P., and Liu, Y. (2009a). CD24 and Siglec10 selectively repress tissue damageinduced immune responses. Science 323, 1722-1725. doi: 10.1126/science. 1168988

Chen, Y., Khanna, S., Goodyear, C. S., Park, Y. B., Raz, E., Thiel, S., et al. (2009b). Regulation of dendritic cells and macrophages by an anti-apoptotic cell natural antibody that suppresses TLR responses and inhibits inflammatory arthritis. J. Immunol. 183, 1346-1359. doi: 10.4049/jimmunol. 0900948

Chockalingam, A., Brooks, J. C., Cameron, J. L., Blum, L. K., and Leifer, C. A. (2009). TLR9 traffics through the Golgi complex to localize to endolysosomes and respond to CpG DNA. Immunol. Cell Biol. 87, 209-217. doi: 10.1038/icb.2008.101

Deane, J. A., Pisitkun, P., Barrett, R. S., Feigenbaum, L., Town, T., 
Ward, J. M., et al. (2007). Control of toll-like receptor 7 expression is essential to restrict autoimmunity and dendritic cell proliferation. Immunity 27, 801-810. doi: 10.1016/j.immuni.2007.09.009

Dennehy, K. M., Ferwerda, G., FaroTrindade, I., Pyz, E., Willment, J. A., Taylor, P. R., et al. (2008). Syk kinase is required for collaborative cytokine production induced through Dectin-1 and Toll-like receptors. Eur. J. Immunol. 38, 500-506. doi: 10.1002/eji.200737741

Diebold, S. S., Kaisho, T., Hemmi, H., Akira, S., and Reis E Sousa, C. (2004). Innate antiviral responses by means of TLR7-mediated recognition of single-stranded RNA. Science 303, 1529-1531. doi: 10.1126/science. 1093616

Diebold, S. S., Massacrier, C., Akira, S., Paturel, C., Morel, Y., and Reis E Sousa, C. (2006). Nucleic acid agonists for Toll-like receptor 7 are defined by the presence of uridine ribonucleotides. Eur. J. Immunol. 36, 3256-3267. doi: 10.1002/eji.200636617

Du, X., Poltorak, A., Wei, Y., and Beutler, B. (2000). Three novel mammalian toll-like receptors: gene structure, expression, and evolution. Eur. Cytokine Netw. 11, 362-371.

Dumitriu, I. E., Baruah, P., Manfredi, A. A., Bianchi, M. E., and RovereQuerini, P. (2005). HMGB1: guiding immunity from within. Trends Immunol. 26, 381-387. doi: 10.1016/j.it.2005.04.009

Eberle, M. E., and Dalpke, A. H. (2012). Dectin-1 stimulation induces suppressor of cytokine signaling 1 , thereby modulating TLR signaling and $\mathrm{T}$ cell responses. J. Immunol. 188, 5644-5654. doi: 10.4049/jimmunol.1103068

Ewald, S. E., Lee, B. L., Lau, L., Wickliffe, K. E., Shi, G. P., Chapman, H. A., et al. (2008). The ectodomain of Toll-like receptor 9 is cleaved to generate a functional receptor. Nature 456, 658-662. doi: 10.1038/nature07405

Ferwerda, G., Meyer-Wentrup, F., Kullberg, B. J., Netea, M. G., and Adema, G. J. (2008). Dectin-1 synergizes with TLR2 and TLR4 for cytokine production in human primary monocytes and macrophages. Cell. Microbiol. 10, 2058-2066. doi: 10.1111/j.1462-5822.2008.01188.x

Fraser, D. A., Laust, A. K., Nelson, E. L., and Tenner, A. J. (2009). C1q differentially modulates phagocytosis and cytokine responses during ingestion of apoptotic cells by human monocytes, macrophages, and dendritic cells. J. Immunol. 183, 6175-6185. doi: 10.4049/jimmunol.0902232

Fukui, R., Saitoh, S., Kanno, A., Onji, M., Shibata, T., Ito, A., et al. (2011). Unc93B1 restricts systemic lethal inflammation by orchestrating Toll-like receptor 7 and 9 trafficking. Immunity 35, 69-81. doi: 10.1016/j.immuni.2011.05.010

Gaipl, U. S., Beyer, T. D., Heyder, P., Kuenkele, S., Bottcher, A., Voll, R. E., et al. (2004). Cooperation between C1q and DNase I in the clearance of necrotic cell-derived chromatin. Arthritis Rheum. 50, 640-649. doi: 10.1002/art.20034

Ganguly, D., Chamilos, G., Lande, R., Gregorio, J., Meller, S., Facchinetti, V., et al. (2009). Self-RNA-antimicrobial peptide complexes activate human dendritic cells through TLR7 and TLR8. J. Exp. Med. 206, 1983-1994. doi: 10.1084/jem.20090480

Goubau, D., Deddouche, S., and Reis, E. S. C. (2013). Cytosolic sensing of viruses. Immunity 38, 855-869. doi: 10.1016/j.immuni.2013.05.007

Gringhuis, S. I., Den Dunnen, J., Litjens, M., Van Het Hof, B., Van Kooyk, Y., and Geijtenbeek, T. B. (2007). C-type lectin DC-SIGN modulates Toll-like receptor signaling via Raf- 1 kinase-dependent acetylation of transcription factor NF-kappaB. Immunity 26, 605-616. doi: 10.1016/j.immuni.2007.03.012

Guttman-Bass, N., Cedar, H., and Panet, A. (1980). Quantification of newly synthesized virus RNA in moloney murine leukaemia virusinfected cells. J. Gen. Virol. 48, 341-350. doi: 10.1099/0022-131748-2-341

Guzylack-Piriou, L., Bergamin, F., Gerber, M., Mccullough, K. C., and Summerfield, A. (2006). Plasmacytoid dendritic cell activation by foot-and-mouth disease virus requires immune complexes. Eur. J. Immunol. 36, 1674-1683. doi: 10.1002/eji.200635866

Haas, T., Metzger, J., Schmitz, F., Heit, A., Muller, T., Latz, E., et al. (2008). The DNA sugar backbone 2' deoxyribose determines toll-like receptor 9 activation. Immunity 28, 315-323. doi: 10.1016/j.immuni.2008.01.013

Hammad, H., Chieppa, M., Perros, F., Willart, M. A., Germain, R. N., and Lambrecht, B. N. (2009). House dust mite allergen induces asthma via Toll-like receptor 4 triggering of airway structural cells. Nat. Med. 15, 410-416. doi: 10.1038/nm.1946
Hanayama, R., Tanaka, M., Miyasaka, K., Aozasa, K., Koike, M., Uchiyama, Y., et al. (2004). Autoimmune disease and impaired uptake of apoptotic cells in MFG-E8-deficient mice. Science 304, 1147-1150. doi: 10.1126/science.1094359

Harshyne, L. A., Zimmer, M. I., Watkins, S. C., and Barratt-Boyes, S. M. (2003). A role for class A scavenger receptor in dendritic cell nibbling from live cells. J. Immunol. 170, 2302-2309.

Hawlisch, H., Belkaid, Y., Baelder, R., Hildeman, D., Gerard, C., and Kohl, J. (2005). C5a negatively regulates toll-like receptor 4-induced immune responses. Immunity 22, 415-426. doi: 10.1016/j.immuni.2005.02.006

Heil, F., Hemmi, H., Hochrein, H. Ampenberger, F., Kirschning, C., Akira, S., et al. (2004) Species-specific recognition of single-stranded RNA via toll-like receptor 7 and 8 . Science 303, 1526-1529. doi: $10.1126 /$ science. 1093620

Hemmi, H., Takeuchi, O., Kawai, T., Kaisho, T., Sato, S., Sanjo, H., et al (2000). A Toll-like receptor recognizes bacterial DNA. Nature 408 740-745. doi: 10.1038/35047123

Henault, J., Martinez, J., Riggs, J. M., Tian, J., Mehta, P., Clarke, L., et al. (2012). Noncanonical autophagy is required for type I interferon secretion in response to DNAimmune complexes. Immunity 37, 986-997. doi: 10.1016/j.immuni. 2012.09.014

Hornung, V., Ellegast, J., Kim, S., Brzozka, K., Jung, A., Kato, H., et al. (2006). 5' $5^{\prime}$-Triphosphate RNA is the ligand for RIGI. Science 314, 994-997. doi: 10.1126/science. 1132505

Ishii, K. J., Coban, C., Kato, H. Takahashi, K., Torii, Y., Takeshita, F, et al. (2006). A Toll-like receptorindependent antiviral response induced by double-stranded Bform DNA. Nat. Immunol. 7, 40-48. doi: $10.1038 /$ ni1282

Ivan, E., and Colovai, A. I. (2006). Human Fc receptors: critical targets in the treatment of autoimmune diseases and transplant rejections. Hum. Immunol. 67 479-491. doi: 10.1016/j.humimm. 2005.12.001

Jahn, P. S., Zanker, K. S., Schmitz, J., and Dzionek, A. (2010). BDCA-2 signaling inhibits TLR-9-agonistinduced plasmacytoid dendritic cell activation and antigen presentation. Cell. Immunol. 265, 15-22. doi: 10.1016/j.cellimm.2010.06.005
Jelinek, I., Leonard, J. N., Price, G. E., Brown, K. N., MeyerManlapat, A., Goldsmith, P. K., et al. (2011). TLR3-specific double-stranded RNA oligonucleotide adjuvants induce dendritic cell cross-presentation, CTL responses, and antiviral protection. J. Immunol. 186, 2422-2429. doi: 10.4049/jimmunol.1002845

Jiang, C., Zhao, M. L., Scearce, R. M., and Diaz, M. (2011). Activationinduced deaminase-deficient MRL/lpr mice secrete high levels of protective antibodies against lupus nephritis. Arthritis Rheum. 63, 1086-1096. doi: 10.1002/art.30230

Jiang, W., and Pisetsky, D. S. (2008). Expression of high mobility group protein 1 in the sera of patients and mice with systemic lupus erythematosus. Ann. Rheum. Dis. 67, 727-728. doi: 10.1136/ard.2007.074484

Joffre, O., Nolte, M. A., Sporri, R., and Reis E Sousa, C. (2009). Inflammatory signals in dendritic cell activation and the induction of adaptive immunity. Immunol. Rev. 227, 234-247. doi: 10.1111/j.1600-065X.2008.00718.x

Joffre, O. P., Segura, E., Savina, A., and Amigorena, S. (2012). Crosspresentation by dendritic cells. Nat. Rev. Immunol. 12, 557-569. doi: $10.1038 /$ nri3254

Jozefowski, S., Arredouani, M., Sulahian, T., and Kobzik, L. (2005). Disparate regulation and function of the class A scavenger receptors SR-AI/II and MARCO. J. Immunol. 175, 8032-8041.

Jozefowski, S., Sulahian, T. H., Arredouani, M., and Kobzik, L. (2006). Role of scavenger receptor MARCO in macrophage responses to $\mathrm{CpG}$ oligodeoxynucleotides. J. Leukoc. Biol. 80, 870-879. doi: 10.1189/jlb.0705357

Kariko, K., Bhuyan, P., Capodici, J., Ni, H., Lubinski, J., Friedman, H., et al. (2004a). Exogenous siRNA mediates sequence-independent gene suppression by signaling through toll-like receptor 3. Cells Tissues Organs 177, 132-138. doi: 10.1159/000079987

Kariko, K., Bhuyan, P., Capodici, J., and Weissman, D. (2004b). Small interfering RNAs mediate sequenceindependent gene suppression and induce immune activation by signaling through toll-like receptor 3 . J. Immunol. 172, 6545-6549.

Kariko, K., Ni, H., Capodici, J., Lamphier, M., and Weissman, D. (2004c). mRNA is an endogenous ligand for Toll-like receptor 3 . 
J. Biol. Chem. 279, 12542-12550. doi: 10.1074/jbc.M310175200

Kariko, K., Buckstein, M., Ni, H., and Weissman, D. (2005). Suppression of RNA recognition by Tolllike receptors: the impact of nucleoside modification and the evolutionary origin of RNA. Immunity 23, 165-175. doi: 10.1016/j.immuni.2005.06.008

Karsten, C. M., Pandey, M. K., Figge, J., Kilchenstein, R., Taylor, P. R., Rosas, M., et al. (2012). Antiinflammatory activity of IgG1 mediated by $\mathrm{Fc}$ galactosylation and association of FcgammaRIIB and dectin-1. Nat. Med. 18, 1401-1406. doi: $10.1038 / \mathrm{nm} .2862$

Kato, H., Takahasi, K., and Fujita, T. (2011). RIG-I-like receptors: cytoplasmic sensors for non-self RNA. Immunol. Rev. 243, 91-98. doi: 10.1111/j.1600-065X.2011.01052.x

Keating, S. E., Baran, M., and Bowie, A. G. (2011). Cytosolic DNA sensors regulating type I interferon induction. Trends Immunol. 32, 574-581. doi: 10.1016/j.it.2011.08.004

Kerrigan, A. M., and Brown, G. D. (2010). Syk-coupled C-type lectin receptors that mediate cellular activation via single tyrosine based activation motifs. Immunol. Rev. 234, 335-352. doi: 10.1111/j.01052896.2009.00882.x

Kim, S. J., Gershov, D., Ma, X., Brot, N., and Elkon, K. B. (2003). Opsonization of apoptotic cells and its effect on macrophage and $\mathrm{T}$ cell immune responses. Ann. N.Y. Acad. Sci. 987, 68-78. doi: 10.1111/j.17496632.2003.tb06034.x

Kim, Y. M., Brinkmann, M. M., Paquet, M. E., and Ploegh, H. L. (2008). UNC93B1 delivers nucleotide-sensing toll-like receptors to endolysosomes. Nature 452, 234-238. doi: 10.1038/nature06726

Kleinman, M. E., Yamada, K., Takeda, A., Chandrasekaran, V., Nozaki, M., Baffi, J. Z., et al. (2008). Sequence- and target-independent angiogenesis suppression by siRNA via TLR3. Nature 452, 591-597. doi: 10.1038/nature06765

Koski, G. K., Kariko, K., Xu, S., Weissman, D., Cohen, P. A., and Czerniecki, B. J. (2004). Cutting edge: innate immune system discriminates between RNA containing bacterial versus eukaryotic structural features that prime for high-level IL-12 secretion by dendritic cells. J. Immunol. 172, 3989-3993.

Lahoud, M. H., Ahmet, F., Zhang, J. G., Meuter, S., Policheni, A. N., Kitsoulis, S., et al. (2012). DEC-205 is a cell surface receptor for $\mathrm{CpG}$ oligonucleotides. Proc. Natl. Acad. Sci. U.S.A. 109, 16270-16275. doi: 10.1073/pnas. 1208796109

Lalli, P. N., Strainic, M. G., Lin, F. Medof, M. E., and Heeger, P. S. (2007). Decay accelerating factor can control $\mathrm{T}$ cell differentiation into IFN-gamma-producing effector cells via regulating local C5a-induced IL-12 production. J. Immunol. 179, 5793-5802.

Lande, R., Gregorio, J., Facchinetti, V., Chatterjee, B., Wang, Y. H., Homey, B., et al. (2007). Plasmacytoid dendritic cells sense self-DNA coupled with antimicrobial peptide. Nature 449, 564-569. doi: 10.1038 /nature06116

Latz, E., Schoenemeyer, A., Visintin, A., Fitzgerald, K. A., Monks, B. G., Knetter, C. F., et al. (2004). TLR9 signals after translocating from the ER to CpG DNA in the lysosome. Nat. Immunol. 5, 190-198. doi: 10.1038/ni1028

Le Bon, A., and Tough, D. F. (2008). Type I interferon as a stimulus for cross-priming. Cytokine Growth Factor Rev. 19, 33-40. doi: 10.1016/j.cytogfr.2007.10.007

Lee, B. L., Moon, J. E., Shu, J. H., Yuan, L., Newman, Z. R., Schekman, R., et al. (2013). UNC93B1 mediates differential trafficking of endosomal TLRs. Elife 2:e00291. doi: 10.7554/eLife.00291

Lee, C. C., Avalos, A. M., and Ploegh, H. L. (2012). Accessory molecules for Toll-like receptors and their function. Nat. Rev. Immunol. 12, 168-179.

Lee, H. K., Lund, J. M., Ramanathan, B., Mizushima, N., and Iwasaki, A. (2007). Autophagy-dependent viral recognition by plasmacytoid dendritic cells. Science 315, 1398-1401. doi: 10.1126/science. 1136880

Leonard, J. N., Ghirlando, R., Askins, J., Bell, J. K., Margulies, D. H., Davies, D. R., et al. (2008). The TLR3 signaling complex forms by cooperative receptor dimerization. Proc. Natl. Acad. Sci. U.S.A. 105, 258-263. doi: 10.1073/pnas.0710779105

Levy, D. E., Marie, I. J., and Durbin, J. E. (2011). Induction and function of type I and III interferon in response to viral infection. Curr. Opin. Virol. 1, 476-486. doi: 10.1016/j.coviro.2011.11.001

Li, K., Fazekasova, H., Wang, N., Peng, Q., Sacks, S. H., Lombardi, G., et al. (2012). Functional modulation of human monocytes derived DCs by anaphylatoxins $\mathrm{C} 3 \mathrm{a}$ and $\mathrm{C} 5 \mathrm{a}$. Immunobiology 217, 65-73.

Limmon, G. V., Arredouani, M., Mccann, K. L., Corn Minor,
R. A., Kobzik, L., and Imani, F. (2008). Scavenger receptor class-A is a novel cell surface receptor for double-stranded RNA. FASEB J. 22, 159-167. doi 10.1096/fj.07-8348com

Liu, L., Botos, I., Wang, Y., Leonard, J. N., Shiloach, J., Segal, D. M., et al. (2008). Structural basis of toll-like receptor 3 signaling with double-stranded RNA. Science 320, 379-381. doi: 10.1126/science.1155406

Londrigan, S. L., Tate, M. D., Brooks, A G., and Reading, P. C. (2012). Cellsurface receptors on macrophages and dendritic cells for attachment and entry of influenza virus. J. Leukoc. Biol. 92, 97-106. doi: 10.1189/jlb.1011492

Lovgren, T., Eloranta, M. L., Bave, U., Alm, G. V., and Ronnblom, L. (2004). Induction of interferonalpha production in plasmacytoid dendritic cells by immune complexes containing nucleic acid released by necrotic or late apoptotic cells and lupus IgG. Arthritis Rheum. 50, 1861-1872. doi: 10.1002/art.20254

Lu, Q., and Lemke, G. (2001). Homeostatic regulation of the immune system by receptor tyrosine kinases of the Tyro 3 family. Science 293, 306-311. doi: 10.1126/science. 1061663

Lund, J., Sato, A., Akira, S., Medzhitov, R., and Iwasaki, A. (2003). Toll-like receptor 9-mediated recognition of Herpes simplex virus-2 by plasmacytoid dendritic cells. J. Exp. Med. 198, 513-520. doi: 10.1084/jem.20030162

Maden, B. E., and Hughes, J. M. (1997). Eukaryotic ribosomal RNA: the recent excitement in the nucleotide modification problem. Chromosoma 105, 391-400. doi: 10.1007/BF02510475

Manfredi, A. A., Capobianco, A., Esposito, A., De Cobelli, F., Canu, T., Monno, A., et al. (2008) Maturing dendritic cells depend on RAGE for in vivo homing to lymph nodes. J. Immunol. 180, 2270-2275.

Matsumoto, M., Funami, K., Tanabe, M., Oshiumi, H., Shingai, M., Seto Y., et al. (2003). Subcellular localization of Toll-like receptor 3 in human dendritic cells. J. Immunol. 171, 3154-3162.

Meyer-Wentrup, F., Cambi, A., Joosten, B., Looman, M. W., De Vries, I. J., Figdor, C. G., et al. (2009). DCIR is endocytosed into human dendritic cells and inhibits TLR8mediated cytokine production. J. Leukoc. Biol. 85, 518-525. doi: 10.1189/jlb.0608352
Mukhopadhyay, S., and Gordon, S. (2004). The role of scavenger receptors in pathogen recognition and innate immunity. Immunobiology 209, 39-49. doi: 10.1016/j.imbio.2004.02.004

Nakamura, K., Miyazato, A., Xiao, G., Hatta, M., Inden, K., Aoyagi, T., et al. (2008). Deoxynucleic acids from Cryptococcus neoformans activate myeloid dendritic cells via a TLR9-dependent pathway. J. Immunol. 180, 4067-4074.

Napirei, M., Karsunky, H., Zevnik, B., Stephan, H., Mannherz, H. G., and Moroy, T. (2000). Features of systemic lupus erythematosus in Dnasel-deficient mice. Nat. Genet. 25, 177-181. doi: 10.1038/76032

Notley, C. A., Brown, M. A., Wright, G. P., and Ehrenstein, M. R. (2011). Natural IgM is required for suppression of inflammatory arthritis by apoptotic cells. J. Immunol. 186, 4967-4972. doi: 10.4049/jimmunol.1003021

Palaniyar, N., Nadesalingam, J., Clark, H., Shih, M. J., Dodds, A. W., and Reid, K. B. (2004). Nucleic acid is a novel ligand for innate, immune pattern recognition collectins surfactant proteins $\mathrm{A}$ and $\mathrm{D}$ and mannosebinding lectin. J. Biol. Chem. 279, 32728-32736. doi: 10.1074/jbc. M403763200

Pang, I. K., Ichinohe, T., and Iwasaki, A. (2013). IL-1R signaling in dendritic cells replaces pattern-recognition receptors in promoting $\mathrm{CD} 8(+) \mathrm{T}$ cell responses to influenza A virus. Nat. Immunol. 14, 246-253. doi: 10.1038/ni.2514

Park, B., Brinkmann, M. M., Spooner, E., Lee, C. C., Kim, Y. M., and Ploegh, H. L. (2008). Proteolytic cleavage in an endolysosomal compartment is required for activation of Toll-like receptor 9 . Nat. Immunol. 9, 1407-1414. doi: 10.1038/ni.1669

Park, B., Buti, L., Lee, S., Matsuwaki, T., Spooner, E., Brinkmann, M. M., et al. (2011). Granulin is a soluble cofactor for toll-like receptor 9 signaling. Immunity 34, 505-513. doi: 10.1016/j.immuni. 2011.01 .018

Parlato, S., Romagnoli, G., Spadaro, F., Canini, I., Sirabella, P., Borghi, P., et al. (2010). LOX-1 as a natural IFN-alpha-mediated signal for apoptotic cell uptake and antigen presentation in dendritic cells. Blood 115, 1554-1563. doi: 10.1182/blood-2009-07-234468

Parroche, P., Lauw, F. N., Goutagny, N., Latz, E., Monks, B. G., Visintin, A., et al. (2007). Malaria hemozoin 
is immunologically inert but radically enhances innate responses by presenting malaria DNA to Tolllike receptor 9. Proc. Natl. Acad. Sci. U.S.A. 104, 1919-1924. doi: 10.1073/pnas.0608745104

Patterson, S., Oxford, J. S., and Dourmashkin, R. R. (1979). Studies on the mechanism of influenza virus entry into cells. J. Gen. Virol. 43, 223-229. doi: 10.1099/0022-1317-43-1-223

Paul, E., and Carroll, M. C. (1999). SAP-less chromatin triggers systemic lupus erythematosus. Nat. Med. 5, 607-608. doi: 10.1038/9450

Peiser, L., Mukhopadhyay, S., and Gordon, S. (2002). Scavenger receptors in innate immunity. Curr. Opin. Immunol. 14, 123-128. doi: 10.1016/S0952-7915(01)00307-7

Peng, Q., Li, K., Anderson, K., Farrar, C. A., Lu, B., Smith, R. A., et al. (2008). Local production and activation of complement up-regulates the allostimulatory function of dendritic cells through C3a-C3aR interaction. Blood 111, 2452-2461. doi: 10.1182/blood-2007-06-095018

Peng, Q., Li, K., Patel, H., Sacks, S. H., and Zhou, W. (2006). Dendritic cell synthesis of $\mathrm{C} 3$ is required for full $\mathrm{T}$ cell activation and development of a Th1 phenotype. J. Immunol. 176, 3330-3341.

Pichlmair, A., Schulz, O., Tan, C. P., Naslund, T. I., Liljestrom, P., Weber, F., et al. (2006). RIGI-mediated antiviral responses to single-stranded RNA bearing $5^{\prime}$-phosphates. Science 314 , 997-1001. doi: 10.1126/science. 1132998

Pisitkun, P., Deane, J. A., Difilippantonio, M. J., Tarasenko, T., Satterthwaite, A. B., and Bolland, S. (2006). Autoreactive B cell responses to RNA-related antigens due to TLR7 gene duplication. Science 312, 1669-1672. doi: 10.1126/science.1124978

Qing, X., Pitashny, M., Thomas, D. B., Barrat, F. J., Hogarth, M. P., and Putterman, C. (2008). Pathogenic anti-DNA antibodies modulate gene expression in mesangial cells: involvement of HMGB1 in anti-DNA antibody-induced renal injury. Immunol. Lett. 121, 61-73. doi: 10.1016/j.imlet.2008.08.007

Randow, F., and Seed, B. (2001). Endoplasmic reticulum chaperone gp96 is required for innate immunity but not cell viability. Nat. Cell Biol. 3, 891-896. doi: 10.1038/ncb1001-891

Robinson, M. J., Sancho, D., Slack, E. C., Leibundgut-Landmann, S., and Reis E Sousa, C. (2006). Myeloid
C-type lectins in innate immunity. Nat. Immunol. 7, 1258-1265. doi: 10.1038/ni1417

Sanjuan, M. A., Rao, N., Lai, K. T., Gu, Y., Sun, S., Fuchs, A., et al. (2006). CpG-induced tyrosine phosphorylation occurs via a TLR9-independent mechanism and is required for cytokine secretion. J. Cell Biol. 172, 1057-1068. doi: 10.1083/jcb. 200508058

Sasai, M., Linehan, M. M., and Iwasaki, A. (2010). Bifurcation of Toll-like receptor 9 signaling by adaptor protein 3. Science 329, 1530-1534. doi: 10.1126/science.1187029

Scaffidi, P., Misteli, T., and Bianchi, M. E. (2002). Release of chromatin protein HMGB1 by necrotic cells triggers inflammation. Nature 418, 191-195. doi: 10.1038/ nature 00858

Schulz, O., Diebold, S. S., Chen, M., Naslund, T. I., Nolte, M. A., Alexopoulou, L., et al. (2005). Toll-like receptor 3 promotes cross-priming to virus-infected cells. Nature 433, 887-892. doi: 10.1038/nature03326

Schulz, O., and Reis E Sousa, C. (2002). Cross-presentation of cellassociated antigens by CD8alpha+ dendritic cells is attributable to their ability to internalize dead cells. Immunology 107, 183-189. doi: 10.1046/j.1365-2567. 2002.01513.x

Schur, P. H. (1977). Complement testing in the diagnosis of immune and autoimmune diseases. Am. J. Clin. Pathol. 68, 647-659.

Schwartz, T., Behlke, J., Lowenhaupt, K., Heinemann, U., and Rich, A. (2001). Structure of the DLM-1-ZDNA complex reveals a conserved family of Z-DNA-binding proteins. Nat. Struct. Biol. 8, 761-765. doi: 10.1038/nsb0901-761

Sekine, H., Reilly, C. M., Molano, I. D., Garnier, G., Circolo, A., Ruiz, P., et al. (2001). Complement component $\mathrm{C} 3$ is not required for full expression of immune complex glomerulonephritis in MRL/lpr mice. J. Immunol. 166, 6444-6451.

Smits, E. L., Ponsaerts, P., Berneman, Z. N., and Van Tendeloo, V. F. (2008). The use of TLR7 and TLR8 ligands for the enhancement of cancer immunotherapy. Oncologist 13, 859-875. doi: 10.1634/theoncologist.2008-0097

Soll, D. (1971). Enzymatic modification of transfer RNA. Science 173, 293-299. doi: 10.1126/science.173.3994.293

Stetson, D. B., and Medzhitov, R. (2006). Recognition of cytosolic DNA activates an IRF3-dependent innate immune response. Immunity 24, 93-103. doi: 10.1016/j.immuni.2005.12.003

Stringer, J. R., Holland, L. E. Swanstrom, R. I., Pivo, K., and Wagner, E. K. (1977). Quantitation of herpes simplex virus type 1 RNA in infected HeLa cells. J. Virol. 21, 889-901.

Stuart, L. M., Takahashi, K., Shi, L., Savill, J., and Ezekowitz, R. A. (2005). Mannose-binding lectin-deficient mice display defective apoptotic cell clearance but no autoimmune phenotype. J. Immunol. 174, 3220-3226.

Sun, L., Wu, J., Du, F., Chen, X., and Chen, Z. J. (2013). Cyclic GMP-AMP synthase is a cytosolic DNA sensor that activates the type I interferon pathway. Science 339, 786-791. doi 10.1126/science. 1232458

Swiecki, M., and Colonna, M. (2010). Unraveling the functions of plasmacytoid dendritic cells during viral infections, autoimmunity, and tolerance. Immunol. Rev. 234, 142-162. doi 10.1111/j.0105-2896.2009.00881.x

Takahashi, K., Shibata, T., AkashiTakamura, S., Kiyokawa, T. Wakabayashi, Y., Tanimura, N. et al. (2007). A protein associated with Toll-like receptor (TLR) 4 (PRAT4A) is required for TLRdependent immune responses. J. Exp. Med. 204, 2963-2976. doi 10.1084/jem.20071132

Takaoka, A., Wang, Z., Choi, M. K., Yanai, H., Negishi, H., Ban, T., et al. (2007). DAI (DLM-1/ZBP1) is a cytosolic DNA sensor and an activator of innate immune response. Nature 448, 501-505. doi: 10.1038/nature 06013

Takizawa, F., Tsuji, S., and Nagasawa, S. (1996). Enhancement of macrophage phagocytosis upon iC3b deposition on apoptotic cells. FEBS Lett. 397, 269-272. doi: 10.1016/S0014-5793(96)01197-0

Tal, M. C., and Iwasaki, A. (2009). Autophagy and innate recognition systems. Curr. Top. Microbiol. Immunol. 335, 107-121. doi: 10.1007/978-3-642-00302-8 5

Theofilopoulos, A. N., Kono, D. H., Beutler, B., and Baccala, R. (2011). Intracellular nucleic acid sensors and autoimmunity. J. Interferon Cytokine Res. 31, 867-886. doi: 10.1089/jir.2011.0092

Tian, J., Avalos, A. M., Mao, S. Y., Chen, B., Senthil, K., Wu, H., et al. (2007). Toll-like receptor 9-dependent activation by DNA-containing immune complexes is mediated by
HMGB1 and RAGE. Nat. Immunol. 8, 487-496. doi: 10.1038/ni1457

Trouw, L. A., Blom, A. M., and Gasque, P. (2008). Role of complement and complement regulators in the removal of apoptotic cells. Mol. Immunol. 45, 1199-1207. doi: 10.1016/j.molimm.2007.09.008

Tuomi, K., Kadaridainen, L., and Soderlund, H. (1975). Quantitation of Semlike Forest virus RNAs in infected cells using 32-P equilibrium labelling. Nucleic Acids Res. 2, 555-565. doi: 10.1093/nar/2.4.555

Viglianti, G. A., Lau, C. M., Hanley, T. M., Miko, B. A., Shlomchik, M. J., and Marshak-Rothstein, A. (2003). Activation of autoreactive B cells by CpG dsDNA. Immunity 19, 837-847. doi: 10.1016/S10747613(03)00323-6

Villadangos, J. A., and Young, L. (2008). Antigen-presentation properties of plasmacytoid dendritic cells. Immunity 29, 352-361. doi: 10.1016/j.immuni.2008.09.002

Wagner, H. (2008). The sweetness of the DNA backbone drives Toll-like receptor 9. Curr. Opin. Immunol. 20, 396-400. doi: 10.1016/j.coi.2008.06.013

Wagstaff, A. J., and Perry, C. M. (2007). Topical imiquimod: a review of its use in the management of anogenital warts, actinic keratoses, basal cell carcinoma and other skin lesions. Drugs 67, 2187-2210. doi: 10.2165/00003495-20076715000006

Wang, J. P., Asher, D. R., Chan, M., Kurt-Jones, E. A., and Finberg, R. W. (2007). Cutting Edge: Antibodymediated TLR7-dependent recognition of viral RNA. J. Immunol. 178, 3363-3367.

Wu, J., Sun, L., Chen, X., Du, F., Shi, H., Chen, C., et al. (2013). Cyclic GMP-AMP is an endogenous second messenger in innate immune signaling by cytosolic DNA. Science 339, 826-830. doi 10.1126/science. 1229963

Xaplanteri, P., Lagoumintzis, G., Dimitracopoulos, G., and Paliogianni, F. (2009). Synergistic regulation of Pseudomonas aeruginosa-induced cytokine production in human monocytes by mannose receptor and TLR2. Eur. J. Immunol. 39, 730-740. doi: 10.1002/eji.200838872

Yanai, H., Ban, T., and Taniguchi, T. (2012). High-mobility group box family of proteins: ligand and sensor for innate immunity. Trends Immunol. 33, 633-640. doi: 10.1016/j.it.2012.10.005

Yanai, H., Ban, T., Wang, Z., Choi, M. K., Kawamura, T., Negishi, H., et al. 
(2009). HMGB proteins function as universal sentinels for nucleic-acidmediated innate immune responses. Nature 462, 99-103. doi: 10.1038/ nature 08512

Yang, D., Chen, Q., Yang, H., Tracey, K. J., Bustin, M., and Oppenheim, J. J. (2007a). High mobility group box-1 protein induces the migration and activation of human dendritic cells and acts as an alarmin. J. Leukoc. Biol. 81, 59-66. doi: 10.1189/jlb.0306180

Yang, Y., Liu, B., Dai, J., Srivastava, P. K., Zammit, D. J., Lefrancois, L., et al. (2007b). Heat shock protein gp96 is a master chaperone for toll-like receptors and is important in the innate function of macrophages. Immunity 26, 215-226. doi: 10.1016/j.immuni. 2006.12.005

Yasuda, K., Rutz, M., Schlatter, B., Metzger, J., Luppa, P. B., Schmitz, F., et al. (2006). CpG motif-independent activation of TLR9 upon endosomal translocation of "natural" phosphodiester DNA. Eur. J. Immunol. 36, 431-436. doi: 10.1002/eji. 200535210

Yasutomo, K., Horiuchi, T., Kagami, S., Tsukamoto, H., Hashimura, C., Urushihara, M., et al. (2001) Mutation of DNASE1 in people with systemic lupus erythematosus. Nat. Genet. 28, 313-314. doi: $10.1038 / 91070$
Zhu, F. G., Reich, C. F., and Pisetsky, D. S. (2001). The role of the macrophage scavenger receptor in immune stimulation by bacterial DNA and synthetic oligonucleotides. Immunology 103, 226-234. doi: 10.1046/j.13652567.2001.01222.x

Conflict of Interest Statement: The authors declare that the research was conducted in the absence of any commercial or financial relationships that could be construed as a potential conflict of interest.

Received: 08 May 2013; paper pending published: 26 May 2013; accepted: 10 July 2013; published online: 30 July 2013.
Citation: Brencicova E and Diebold SS (2013) Nucleic acids and endosomal pattern recognition: how to tell friend from foe? Front. Cell. Infect. Microbiol. 3:37. doi: 10.3389/fcimb.2013.00037

Copyright (c) 2013 Brencicova and Diebold. This is an open-access article distributed under the terms of the Creative Commons Attribution License (CC BY). The use, distribution or reproduction in other forums is permitted, provided the original author(s) or licensor are credited and that the original publication in this journal is cited, in accordance with accepted academic practice. No use, distribution or reproduction is permitted which does not comply with these terms. 